\title{
RESPONSABILIDAD PRECONTRACTUAL POR RUPTURA INJUSTIFICADA DE NEGOCIACIONES
}

\author{
"IIMÉNEZ MIRA, DAVID ALEJANDRO CON ARMIJO CERDA, \\ ANTONIO DE LOS ÁNGELES” CORTE SUPREMA, ROL 1872/2010.
}

\author{
Lilian C. San Martín Neira ${ }^{1}$
}

\begin{abstract}
RESUMEN: En la sentencia comentada la Corte Suprema se pronuncia sobre la procedencia, requisitos, naturaleza jurídica y efectos de la responsabilidad civil por ruptura injustificada de negociaciones. Al efecto establece que durante las negociaciones los futuros contratantes tienen el deber de comportarse de buena fe. Quien quebrante dicho deber ha de indemnizar los daños causados y dicha indemnización se rige por las reglas de la responsabilidad extracontractual.
\end{abstract}

Palabras Clave: Responsabilidad precontractual, ruptura injustificada de negociaciones, daños en las tratativas preliminares.

ABSTRACT: In the commented sentence, the Supreme Court pronounces about the applicability, requirements, legal nature and effects of the liability for unjustified breach of negotiations. The Court states that during the negotiations the parties have the duty to act according to the good faith. Anyone who violates that duty has to compensate damages and the compensation is governed by the rules of the Chilean tort law.

Key Words: pre-contractual liability, unjustified rupture of negotiations, damages during the negotiations.

\section{1. $\mathrm{HECHOS}$}

Las partes del juicio iniciaron serias negociaciones para celebrar un futuro contrato de compraventa sobre un inmueble ubicado en la comuna de Cartagena, correspondiente a un establecimiento comercial de giro supermercado. Frente a la imposibilidad técnica de celebrar el contrato definitivo de compraventa, las partes acordaron suscribir un contrato de promesa de compraventa.

Según fue acreditado en el juicio, ambas partes estaban contestes en la intención de celebrar un contrato de compraventa y en el precio, ascendiente a la suma de $\$ 125.000 .000$. Sin embargo, tenían desavenencias en cuanto al pago del saldo de precio, ascendiente a $\$ 25.000 .000$, además del contenido de la cláusula penal.

Las tratativas preliminares entre el demandante y el demandado se encontraban en una fase avanzada, disponiéndose a concurrir a celebrar el contrato de promesa de compraventa a la notaría. Sin embargo, conforme emana de la prueba confesional rolante en autos,

1 Universidad Alberto Hurtado, correo electrónico liliansanmartinneira@gmail.com. Este trabajo forma parte del proyecto Anillo de Investigación Asociativa en Ciencias Sociales, "Estudios Histórico-Dogmáticos de Derecho Patrimonial Privado: una mirada a los artículos de los libros II y IV del Código Civil de Chile". SOC 1111, de Conicyt. 
el demandado se negó a firmar la escritura de promesa de compraventa fundándose en "que no quiso porque no convenía"(Considerando noveno).

A juicio de la Corte Suprema, "esta declaración demuestra claramente la mala fe del demandado en su actuar, pues su desistimiento es intempestivo y sin justificación legítima, debiendo reparar los perjuicios causados por su actuar negligente" (Ibidem).

Atendida la naturaleza solemne del contrato de promesa, no obstante haberse formado el consentimiento, el demandado no ha incurrido en incumplimiento de contrato, sino simplemente en una ruptura injustificada de negociaciones. En consecuencia, el negociante afectado solicitó indemnización de perjuicios por 72 millones de pesos, invocando responsabilidad precontractual. La Corte Suprema acogió parcialmente la demanda.

\section{DOCTRINA}

"El ilícito precontractual no consiste en haberse resistido a celebrar el contrato, sino en haber negociado de mala fe o con grave desaprensión respecto de los intereses de la otra parte, como en este caso sería respecto de la ocasión de las rupturas de las negociaciones. En consecuencia, el perjuicio está dado por los efectos que se siguen de haber puesto la confianza en la diligencia y buena fe de la contraparte, de modo que la pretensión indemnizatoria tiene por finalidad que el demandado ponga al actor en la situación en que se encontraría si esos específicos ilícitos no se hubieran realizado”. (Considerando octavo).

\section{COMENTARIO}

En la doctrina y jurisprudencia nacionales se advierte una creciente atención en la llamada responsabilidad precontractual ${ }^{2}$, la cual todavía presenta diversos aspectos debatidos. La sentencia aquí reseñada tiene el mérito de hacerse cargo de tales aspectos y adoptar una posición clara y fundamentada sobre cada uno de ellos, a saber: a) fundamento de la responsabilidad precontractual; b) naturaleza jurídica de la responsabilidad precontractual, contractual o extracontractual; c) requisitos de procedencia de la responsabilidad precontractual; y d) la extensión del daño resarcible o quantum respondeatur. Ese será el orden que seguirá este comentario.

\subsection{Fundamento de la RESPONSABILIDAd PRECONTRACTUAL}

La responsabilidad precontractual supone la ausencia de un vínculo obligatorio previo entre las partes, ya sea porque estaban todavía en la fase de negociaciones o bien porque -como en este caso- para que el contrato se perfeccionara era necesario el cumplimiento de una solemnidad o bien la entrega de la $\operatorname{cosa}^{3}$. En todo caso, ella no surge

\footnotetext{
2 Para un panorama general del argumento en el ámbito nacional cabe citar a: Rosende (1979); Domínguez (1996) pp. 179-185; Domínguez (1998) pp. 187-188; Barros (2006) pp. 1000 ss.; Zuloaga (2006); De la Maza Gazmuri (2006) pp. 131-158; Segura (2007) pp. 345-362; Barrientos (2008); Celedón y Silberman (2010).

3 En efecto, la responsabilidad precontractual no surge cuando las partes no han alcanzado el consentimiento, sino cuando el contrato aún no se ha perfeccionado. En este sentido resulta criticable la opinión de la Corte de
} 
entre extraños, sino entre personas que habían entrado en contacto con miras a la celebración de un contrato. De ahí que tradicionalmente se haya aceptado que la responsabilidad precontractual no se funda simplemente en el deber genérico de no dañar a otro, neminem leadere, sino que se han esgrimido diversos fundamentos o criterios de atribución para sustentarla ${ }^{4}$. Así, se la ha considerado un abuso del derecho, una manifestación de la prohibición de venire contra factum proprium, una aplicación de la noción culpa in contrahendo y, por último, una infracción al deber de comportarse de buena fe durante las negociaciones.

La sentencia comentada se inclina por el último de los fundamentos enunciados y asume la existencia de un deber de negociar de buena fe. En tal sentido, siguiendo a Enrique Barros, la Corte sostuvo que "entre los deberes precontractuales de quienes participan de las tratativas preliminares está el deber de lealtad, que exige llevar adelante las negociaciones de buena fe, esto es, con el propósito efectivo de celebrar un contrato; y que también suponen deberes de cuidado al terminar la negociación, cuando se ha creado en la contraparte la confianza de que se celebrará el contrato. El deber de negociar de buena fe exige someter el juego puramente estratégico, caracterizado porque cada parte procura su propio interés, a los límites de los deberes mínimos de lealtad que se pueden esperar de un contratante honesto" (considerando tercero).

En síntesis, según el sentenciador, el fundamento último de la responsabilidad precontractual es la violación del deber de negociar de buena fe, el cual no constituye una obligación precisa, sino solamente un deber genérico de conducta cuya "concreción depende de la particular relación que surge entre las partes a partir de la oferta o de las primeras tratativas contractuales" (considerando tercero).

Sin embargo, como se desprende de los requisitos de procedencia establecidos en la misma sentencia (vid infra), la Corte deja ver que la configuración de la responsabilidad se funda también en una defraudación de la confianza creada en la otra parte y en un abuso del derecho de libertad contractual, todas especificaciones de la buena fe objetiva. Por tanto, puede decirse simplemente que "la buena fe es el fundamento de la responsabilidad precontractual" (Cfr. Corte Suprema, Urrea con Corpbanca, Rol No 218/2011, considerando decimotercero $)^{5}$.

\footnotetext{
Apelaciones de Puerto Montt que en fallo de 15 de julio de 2008 sostuvo: "que en la formación del consentimiento nuestro ordenamiento jurídico delimita la responsabilidad contractual de aquella extracontractual, así las tentativas previas se caracterizan por ser una etapa anterior al contrato, y por ende la formación del consentimiento, recurriéndose tan solo que las partes desarrollen actividades con miras a explorar el futuro contrato". (Cfr. Sociedad Comercial e Inmobiliaria Beckna Limitada con Corporación Municipal de Ancud y otros, (2008): Corte de Apelaciones de Puerto Montt, 15 de julio de 2008 (acción de indemnización de perjuicios), CL/ JUR/5792/2008, Rol 52/2008 (considerando octavo). Tal afirmación es válida solamente respecto de los contratos puramente consensuales, no respecto de los reales o solemnes, en que aun habiéndose formado el consentimiento las partes no están todavía obligadas.

4 Para todos véase Celedón y Foster (2010) pp. 56 ss.

5 En este mismo sentido se pronunció la Corte de Apelaciones de Concepción en 1996. Véase comentario en Domínguez (1996) pp. 179 ss.
} 


\section{a) Naturaleza jurídica de la responsabilidad precontractual}

Es bien sabido que la primera obra que abordó abiertamente el argumento de la responsabilidad precontractual fue la clásica obra de Jhering "De la culpa in contrahendo"6. Asimismo, es sabido que en su propuesta Jhering sostuvo que la culpa in contrahendo da lugar responsabilidad contractual. En efecto, siguiendo a las fuentes romanas, Jhering veía imposible que el daño sufrido en virtud de un contrato frustrado pudiera ser calificado de daño aquiliano, pues este tenía una forma limitada, referido a cosas "dotadas de exterioridad" (personas o cosas); por su parte, tampoco era procedente la actio doli, pues, como su nombre lo indica, esta solo procedía en caso de dolo, el cual debía ser entendido como animus nocendi ${ }^{7}$.

El sistema planteado por Jhering fue acogido en Alemania, gracias a la tipicidad de la responsabilidad extracontractual establecida en el BGB, y que ha sido mantenida por el legislador alemán, incluso con posterioridad a la ley de modernización del derecho de las obligaciones de 2002.

En Chile, en cambio, la responsabilidad extracontractual no es típica, por consiguiente, no hay barreras legislativas que impidan afirmar que la culpa in contrahendo da origen a responsabilidad extracontractual. Sin embargo, al igual que ha sucedido en otros países con ordenamientos similares al chileno, la doctrina se ha puesto el problema de la naturaleza de la responsabilidad precontractual y ha sostenido posiciones contradictorias al respecto ${ }^{8}$, llegando incluso a abogar por la responsabilidad precontractual como un tertium genus, a medio camino entre la responsabilidad contractual y extracontractual ${ }^{9}$. Sin embargo, la doctrina ampliamente mayoritaria aboga por el carácter extracontractual de la responsabilidad precontractual.

Así, manteniendo la tendencia mayoritaria, la sentencia que se comenta sostiene abiertamente la naturaleza extracontractual de la responsabilidad precontractual ${ }^{10}$. Al efecto, siguiendo a Enrique Barros ${ }^{11}$, señala: "mientras no haya consentimiento, no nacen obligaciones contractuales entre las partes, pues estas tienen por antecedente necesario la voluntad de obligarse. Sin embargo, durante la negociación del contrato surgen para las partes deberes de cuidado. Si las partes regulan sus negociaciones mediante acuerdos en principio u otras convenciones preliminares, los deberes recíprocos devienen en obligaciones contractuales, en los términos de esos acuerdos. A falta de esos contratos, los deberes de cuidado que las partes deben emplear en la negociación están impuestos por

\footnotetext{
6 En la realización de este comentario se tuvo a la vista la obra de Jhering en su traducción italiana de 2005. Véase Von JHering (2005) .

7 Véase JHERing (2005) pp. 47 ss.

8 Para todos, Véase Celedón y Silberman (2010) pp. 132 ss.

9 En este sentido Zuloaga (2006) pp. 124 ss.

10 Cabe destacar, sin embargo, que la sentencia tiene un voto de prevención del Ministro Muñoz, el cual no comparte la naturaleza extracontractual de la responsabilidad precontractual y sostiene que es de naturaleza contractual. Al efecto señala que "la responsabilidad precontractual, si bien participa de la extracontractual en la inexistencia de vínculo [previo], adquiere sus contornos más apropiados en la de carácter contractual, que, además, en concepto de quien previene constituye el régimen de responsabilidad general y subsidiario en el derecho civil" (consideración $6^{a}$ ).

11 Véase Barros (2006) pp. 1003 ss.
} 
el derecho, y no por la convención, de modo que la responsabilidad precontractual es extracontractual" (considerando sexto).

En consecuencia, la Sentencia asume que en sede precontractual el deber de comportarse de buena constituye una especificación del precepto más general de neminem leadere, intensificado por el hecho que las partes no son extraños, sino que están en vías de celebrar un contrato.

\section{b) Requisitos de procedencia de la responsabilidad precontractual}

Como se dijo, no obstante su naturaleza extracontractual, el fundamento de la responsabilidad precontractual es el quebrantamiento al deber de buena fe objetiva ${ }^{12}$ que impera durante todo el iter contractual ${ }^{13}$. Sin embargo, es necesario cuestionarse hasta qué punto la buena fe objetiva obliga a las partes a mantener la palabra (todavía no empeñada) y continuar con las negociaciones hasta la conclusión del contrato. Es necesario determinar cuándo, o cómo, las partes llegan al punto de no retorno en virtud del cual ya no les resulta legítimo retirarse unilateralmente de las negociaciones. En tal sentido la Sentencia señala que "no se discute el derecho de retirarse de las tratativas, pues sería un derecho absoluto (...) Lo que se discute es bajo qué condiciones el retiro genera obligación de indemnizar el daño causado" (considerando segundo).

Siguiendo a Marcelo Barrientos ${ }^{14}$, la Sentencia establece que "los requisitos para que opere” la responsabilidad precontractual son: “a) La creación de una razonable confianza en la conclusión o perfeccionamiento del contrato proyectado; b) El carácter injustificado e intempestivo de la ruptura de los tratos preliminares; c) La producción de un daño en el patrimonio de una de las partes y d) La relación de causalidad entre el daño al patrimonio por un lado y la confianza que fue promovida y resultó defraudada por el otro negociante" (considerando séptimo).

En consecuencia, de la Sentencia se desprende que los negociantes son libres para decidir arbitrariamente si celebrar o no el contrato que están negociando, pero solo mientras no hayan generado en el otro negociante la razonable confianza de que concluirán el proceso de negociación positivamente. Arribados a este punto, los negociantes dejan de tener libertad absoluta para decidir si concluirán o no el contrato y el retiro unilateral solo es

12 El Fallo da una gran preponderancia a la buena fe, en su aspectos objetivo y subjetivo y concluye que "la buena fe, al ser un principio general del derecho y en especial de la contratación civil, se debe considerar su aplicación en todo el iter contractual, desde la etapa de tratativas preliminares, la celebración del contrato, ejecución del mismo, interpretación contractual e inclusive el período postcontractual" (considerando cuarto).

13 En sentido similar la Corte de Apelaciones Puerto Montt sostuvo que "una condición de procedencia de la pretensión del demandante es que haya existido por parte de los demandados una infracción a la obligación de negociar de buena fe, imputable a culpa o dolo y que como consecuencia, el incumplimiento del deber de actuar de buena fe que cause daños a la otra parte hará surgir la responsabilidad del agente de indemnizarlos, acorde a lo estatuido en los artículos 44, 706, 707, 2284 y 2314 del Código Civil”. Cfr. Sociedad Comercial e Inmobiliaria Beckna Limitada con Corporación Municipal de Ancud y otros (2008), considerando decimoctavo.

14 Véase Barrientos (2008) p. 51. 
legítimo cuando resulte justificado, es decir, cuando hayan razones que autoricen la ruptura de las negociaciones; en caso contrario, surge la responsabilidad precontractual ${ }^{15}$.

\section{c) Quantum respondeatur de la responsabilidad precontractual}

Establecida la procedencia de la responsabilidad precontractual (an debeatur), el aspecto más relevante está dado por sus consecuencias, es decir, el alcance o extensión del daño resarcible (quantum respondeatur). En tal sentido la Sentencia afirma "que en ausencia de estipulaciones sobre gastos o riesgos entre los precontratantes, que es lo que ha acontecido en el caso en estudio, cabe determinar qué tipo de perjuicios son indemnizables" (considerando octavo).

Siguiendo con el razonamiento, la Corte sostiene que "el ilícito precontractual no consiste en haberse resistido a celebrar el contrato, sino en haber negociado de mala fe o con grave desaprensión respecto de los intereses de la otra parte, como en este caso sería respecto de la ocasión de las rupturas de las negociaciones. En consecuencia, el perjuicio está dado por los efectos que se siguen de haber puesto la confianza en la diligencia y buena fe de la contraparte, de modo que la pretensión indemnizatoria tiene por finalidad que el demandado ponga al actor en la situación en que se encontraría si esos específicos ilícitos no se hubieran realizado. Por estos motivos, la regla general será que el interés protegido no es el beneficio que el contrato habría reportado al demandante si hubiese llegado a celebrar$\mathrm{se}^{16}$, sino los daños que se siguen del ilícito, como son los costos de negociación y los que se derivan de la confianza creada en la contraparte y contrariada por la mala fe del demandado" (considerando octavo).

Así, como es la tradición en la materia, la Sentencia limita el resarcimiento del daño al interés negativo. Sin embargo, siguiendo a Hugo Rosende ${ }^{17}$, tiene el buen cuidado de no confundir interés negativo con daño emergente, al contrario, sostiene que "deben indemnizarse todos los gastos y perjuicios que sean una consecuencia directa de la revocación (...). Habrá que entender que los perjuicios indemnizables incluyen el daño emergente, el lucro cesante e incluso el daño moral, siempre que sean consecuencia directa de la revocación"

\footnotetext{
15 En el mismo sentido y de manera más clara se pronunció la Corte Suprema la cual señaló: "Que si bien el retiro durante las tratativas contractuales es un derecho de las partes, ello no excluye la responsabilidad por los daños que se generen por aquel que se desiste sin causa o arbitrariamente. La buena fe es el fundamento de la responsabilidad precontractual. En lo tocante a la ruptura de las tratativas se ubica en el campo de lo subjetivo el determinar lo injusto o injustificado de su ruptura (...)". Cfr. Urrea Fuentes Cristian con Corpbanca (2012): Corte Suprema, 12 de abril de 2012 (acción de indemnización de perjuicios), CL/JUR/788/2012, Rol No 218/2011, considerando decimotercero.

Con anterioridad en el mismo sentido se había pronunciado la Corte de Apelaciones de Concepción, la cual señaló: "los tratos preliminares no obligan a contratar, pues ello sería contrario a la libertad contractual; pero sí a indemnizar los perjuicios si las negociaciones se interrumpen abruptamente, sin causa justificada, porque la libertad contractual no constituye un derecho absoluto, de donde se sigue que no puede ejercerse en forma abusiva, causando con ello daño a la contraparte". Cfr. Sociedad Cruz de la Barra con Comar S.A., Rol 1530/1996. Comentada en Domínguez (1998) pp. 187 ss.

16 En esta parte del Fallo resulta criticable el uso de la expresión regla general, pues da a la idea de que hay casos en que el interés protegido sí son los beneficios que el otro negociante esperaba obtener del contrato, lo que no es así.

17 Véase Rosende (1979) p. 99.
} 
(considerando octavo). En consecuencia, la sentencia admite que en el interés negativo va incluido también el lucro cesante derivado de la pérdida de una oportunidad, como lo sería una oferta rechazada a causa de las negociaciones.

Siguiendo también a Hugo Rosende, la sentencia agrega que "el único límite en la indemnización está en que la parte no puede quedar en mejor posición que en la que habría quedado de celebrarse el contrato" (considerando octavo). Este aspecto resulta interesante, pues implica que el demandado podrá probar, por ejemplo, que de haber celebrado el contrato frustrado el demandante habría obtenido pérdidas, en lugar de ganancias y, en tal caso, no procede ni siquiera la indemnización del daño emergente ${ }^{18}$.

\section{OBSERVACIONES FINALES}

La sentencia comentada constituye una referencia obligada en responsabilidad precontractual, pues establece las directrices del máximo tribunal en la materia. En efecto, en ella se encuentran decantadas las discusiones doctrinarias más importantes en torno al argumento.

En tal sentido: a) señala que el fundamento de la responsabilidad precontractual es la buena fe; b) reitera que se trata de responsabilidad extracontractual; c) establece los requisitos de procedencia de la responsabilidad precontractual la cual, además de los requisitos propios de la responsabilidad civil, exige i) el quebrantamiento de la confianza razonable creada en la contraparte y ii) la falta de justificación en el retiro de las negociaciones; d) limita la cuantía del resarcimiento al interés negativo, pero incluye aquí el lucro cesante que sea consecuencia de la negociación frustrada.

\section{BIBLIOGRAFÍA}

Barrientos Zamorano, Marcelo (2008): Daños y deberes en las tratativas preliminares de un contrato (Santiago, Editorial Legal-Publishing).

Barros Bourie, Enrique (2006): Tratado de responsabilidad extracontractual (Santiago, Editorial Jurídica de Chile).

Celedón Förster, Rosario y Silberman Veszpremi, Patricia (2010): Responsabilidad precontractual por ruptura de negociaciones contractuales (Santiago, Editorial Jurídica de Chile).

De la Maza Gazmuri, Iñigo (2006): "El retiro unilateral como un caso de responsabilidad precontractual”, en De la Maza, Iñigo (edit.), Temas de Contratos. Cuadernos de análisis jurídico III (Santiago, Universidad Diego Portales) pp. 131-158.

Domínguez Águila, Ramón et al. (1998): “Comentario de jurisprudencia, No 3: Responsabilidad precontractual. Ruptura injustificada de negociaciones. Daños causados”, Revista de Derecho Universidad de Concepción, No 204, año LXVI: pp. 187-188.

18 En este sentido se ha dicho que si: "por ejemplo, el infractor llegara a demostrar, con una seguridad rayana en la certeza, que la ruptura de las negociaciones ha librado a la otra parte de una operación que le habría reportado pérdidas, no resultaría justo imponer al repetido infractor, aun doloso, responsabilidad precontractual alguna”. Cfr. Pantaleón (2011) p. 909. 
Domínguez Benavente, Ramón et al. (1996): “Comentario de jurisprudencia, No 1: Responsabilidad precontractual extracontractual. Retiro inmotivado de las negociaciones preliminares", Revista de Derecho Universidad de Concepción, N 199, año LXIV: pp. 179-185.

Pantaleón, Fernando (2011): "Responsabilidad precontractual: propuestas de regulación para un futuro Código Latinoamericano de Contratos”, Anuario de Derecho Civil, tomo LXIV, fasc. III: pp. 897-929.

Rosende Álvarez, Hugo (1979): Algunas consideraciones sobre la responsabilidad precontractual (Valparaíso Editorial Universitaria).

Segura Riveiro, Francisco (2007): "El interés contractual indemnizable en las hipótesis de responsabilidad precontractual”, en Corral, Hernán y Rodríguez María Sara (edit.), Estudios de Derecho Civil II. Jornadas Nacionales de Derecho Civil, Olmue, 2006 (Santiago, Abeledo Perrot) pp. 345-362.

Von Jhering, Rudolf (2005): Della culpa in contrahendo. Ossia del risarcimento del danno nei contratti nulli o non giunti a perfezione (trad. Federico Prochchi, Napolés, Editorial Jovene).

Zuloaga Ríos, Margarita (2006): Teoría de la responsabilidad precontractual: aplicación en la formación del consentimiento de los contratos (Santiago, Editorial LexisNexis).

\section{JURISPRUDENCIA CITADA}

Sociedad Comercial e Inmobiliaria Beckna Limitada con Corporación Municipal de Ancud y otros (2008): Corte de Apelaciones de Puerto Montt, 15 de julio de 2008 (acción de indemnización de perjuicios), CL/JUR/5792/2008, Rol 52/2008.

Urrea Fuentes Cristian con Corpbanca (2012): Corte Suprema, 12 de abril de 2012 (acción de indemnización de perjuicios), CL/JUR/788/2012, Rol No 218/2011. 